\title{
Composición enzimática del veneno de la raya (Potamotrygom schroederi)
}

\section{Enzymatic composition of stingray (Potamotrygom schroederi) venom}

\author{
Rodríguez Ospina Nadia y Ramírez Ávila Jaime ${ }^{2}$ \\ ${ }^{1} \mathrm{MVZ}$. Universidad de los Llanos y \\ ${ }^{2}$ Biol. Instituto Nacional de salud, Laboratorio de sueros \\ agroforesteria@unillanos.edu.co
}

Recibido 12 de Diciembre 2013, Aceptado 11 de Abril 2014

\section{RESUMEN}

Las rayas de agua dulce (familia potamotrygonidae), son peces que habitan los ríos de Colombia. Ningún estudio se ha realizado basado en la problemática de la accidentabilidad y el envenenamiento que ocasionan estos animales. Este trabajo pretende dar un aporte para el conocimiento de la composición enzimática del veneno de la raya Potamotrygom schroederi, proponiéndose la búsqueda de 6 enzimas: proteasas, 5'-nucleotidasa, fosfatasas ácida y alcalina, fosfolipasa $A_{2}$ y hialuronidasa. El veneno fue aislado de la raya Potamotrygom schroederi, obtenida del río Negro (Meta). Las rayas fueron capturadas y bajo manejo anestésico se retiró el arpón y posteriormente dejadas en libertad, los arpones se almacenaron en nitrógeno líquido y posteriormente fueron liofilizados, los cuales fueron raspados y su contenido pesado y homogenizado, luego se centrifugaron a 10.000 revoluciones por 10 minutos a $4^{\circ} \mathrm{C}$, obteniéndose por lisis de las células, el veneno. Se trabajó como control positivo de los ensayos la hialuronidasa purificada, el veneno de Bothrops asper de la región de Armero, obtenido por ordeño de las serpientes mantenidas en cautiverio en el serpentario del Instituto Nacional de Salud. El control negativo para todos los ensayos fue un blanco. Las diferentes técnicas enzimáticas fueron estandarizadas y los resultados obtenidos determinan la presencia de 4 de las 6 enzimas propuestas inicialmente: proteasas, 5-Nucleotidasa, fosfatasa alcalina y hialuronidasa. Adicionalmente se realizó un perfil de accidentalidad en el Hospital Departamental de Villavicencio, 
encontrándose 20 casos, con la presencia de síntomas tales como, necrosis tisular, edema y dolor, lo cual desencadenó en la amputación del miembro afectado. Los resultados obtenidos indican que las rayas son animales venenosos que influyen de manera directa en la salud humana, debido a que su veneno posee una mezcla enzimática que ocasiona disturbios graves en los diferentes sistemas, sin existir un tratamiento efectivo, razón por la cual deben ser considerados como un problema de salud pública, incorporándolos dentro del grupo de animales venenosos de Colombia.

Palabras clave: Raya, Potamotrygom schroederi, toxina.

\section{ABSTRACT}

The stingrays (family potamotrygonidae) are fish that inhabit the rivers of Colombia. No study has been conducted based on the problem of accidents and poisoning causing these animals. This work aims to contribute to the knowledge of the composition of the venom enzyme stripe Potamotrygom schroederi, proposing search 6 enzymes: protease, 5'-nucleotidase, acid and alkaline phosphatases, phospholipase $A_{2}$ and hyaluronidase. The venom was isolated stripe Potamotrygom schroederi, obtained from Negro river (Meta). The stripes were captured and under anesthetic management harpoon was removed and then left alone, the barbs were stored in liquid nitrogen and then were lyophilized, which were scraped and weighed and homogenized content, then centrifuged at 10,000 rpm for 10 minutes at $4^{\circ} \mathrm{C}$, obtaining by lysis of the cells, the poison. It worked as a positive control for testing the purified hyaluronidase, Bothrops asper venom in the region of Armero, obtained by milking the snakes kept in captivity at the Serpentarium of the National Institute of Health. The negative control for all tests was a target. The different enzymatic techniques were standardized and results determine the presence of 4 of the 6 enzymes originally proposed: proteases, 5nucleotidase, alkaline phosphatase and hyaluronidase. Additionally, a profile accident took place in the Departmental Hospital Villavicencio, finding 20 cases, with the presence of symptoms such as tissue necrosis, edema and pain, 
triggering in amputation of the affected limb. The results indicate that the stripes are poisonous animals that have a direct bearing on human health, because their venom has an enzyme mixture that causes serious disturbances in various systems, with no effective treatment, why should be considered a public health problem by incorporating within the group of venomous animals of Colombia.

Keywords: Stingray, Potamotrygom schroederi, toxin.

\section{INTRODUCCIÓN}

Las rayas de agua dulce, género Potamotrygom se encuentran en la mayoría de los ríos de Colombia, describiéndose 6 especies: $P$. magdalenae, $P$. yepezi, $P$. motoro, P. hystrix, P. schroederi y P. laticeps (Petrovicky, 1990; Mojica, 1999). Las rayas en su cola poseen un mecanismo de defensa contra los predadores (el arpón), el cual contiene una cubierta tegumentaria (epidermis), que produce veneno, en el que se observa la presencia de enzimas como la $5^{\prime}$-Nucleotidasa y fosfodiesterasa en rayas de mar Urobatis halleri y Dasyastis americana (Meir y Acott Harrefeld, 1995). En Colombia no se ha realizado trabajos para la determinación de la presencia o ausencia de enzimas en el veneno de las rayas de agua dulce.

En Colombia no se ha realizado trabajos para la determinación de la presencia o ausencia de enzimas en el veneno de las rayas de agua dulce y se han registrado anualmente más de 2.000 casos de accidentes ocasionados por estos peces de agua dulce (Grenard, 1999). En otras zonas del mundo, como es el caso de la costa Norte Americana se han informado 750 picaduras por año, ocasionadas por rayas de mar, pastinacas (Dayastis americana) (The Merck, 1999).

La alta accidentalidad que estos animales ocasionan en Colombia anualmente y las sus consecuencias desagradables como: como: edema, necrosis, amputaciones y muerte, hace necesario conocer desde el punto de vista científico aspectos del envenenamiento, para no continuar con procedimientos poco ortodoxos, que desvirtúan el verdadero curso del accidente, por lo tanto es 
importante realizar estudios que permitan conocer la composición enzimática de su veneno, con el fin de encontrar un antídoto adecuado para contrarrestar su efecto nocivo (Otero et al., 2002).

Los venenos de animales, generalmente son mezclas biológicamente activas de polipéptidos y proteínas (Pineda y Rengifo, 2002), aminoácidos libres, ácidos orgánicos (especialmente citrato), azúcares (monosacáridos como la glucosa, galactosa y manosa), lípidos (ácidos grasos), nucleósidos, nucleótidos (adenosina, guanosina, inosina), aminas biogénicas (acetilcolina y otras colaminas), agua, detritos celulares, iones y bacterias (Meier y Stocker, 1995; Otero et al., 2002), que provocan envenenamientos con sintomatología local como edema, flictenas, necrosis de tejido muscular y conectivo; y manifestaciones sistémicas que pueden generar nefrotoxicidad y generalmente involucran alteración de la hemostasia con pequeños sangrados o choque cardiovascular por hemorragia severa (Otero et al., 2002; Santoro y Sanos, 2004).

\section{METODOLOGÍA}

El estudio se realizó en el Laboratorio de Sueros del Instituto Nacional de Salud, localizado en la ciudad de Bogotá. Se capturaron 20 ejemplares, los cuales fueron sometidos a restricción química, introduciendo al animal en una pileta con metasulfonato de tricaina a una dosis de $0.01 \%$ (ASU, 1999). Por medio de bisturí se extrajo el arpón, el cual fue almacenado para su conservación en nitrógeno líquido, con el fin de evitar la desnaturalización de los venenos, los peces vivos y recuperados del anestésico fueron devueltos al río.

Los arpones fueron raspados con bisturí para la obtención del veneno, el material colectado se sometió a liofilización, siendo suspendido en buffer fosfato 50 milimoles $(\mathrm{mM}), \mathrm{pH} 7.0$, con un contenido de cloruro de sodio $150 \mathrm{mM}$. Finalmente, se centrífugo a 10.000 revoluciones durante 10 minutos y el sobrenadante colectado se utilizó como fuente de enzimas para realizar los diferentes ensayos. 
Determinación de proteasas. Se utiliza como substrato caseína que al reaccionar con las proteasas, produce la liberación de aminoácidos (AA), estos $A A$ no son precipitados por el ácido tricloroacético quedando en el sobrenadante, produciendo cambios de absorbancia que son leídos en espectrofotómetro a 280 nanómetros $(\mathrm{nm})$. La caseína $(0.5 \mathrm{ml}$ al $2 \%)$ se hizo reaccionar con la muestra a analizar $(0.5 \mathrm{ml})$, durante 15 minutos; la reacción se detuvo con ácido tricloroacético (1 $\mathrm{ml}$ al 10\%), para precipitar las proteínas presentes en la reacción, se agitó y se dejó en reposo por 30 minutos, luego de los cuales se centrifugó dos ocasiones a 1.665 revoluciones durante 10 minutos y luego se extrajo el sobrenadante cada vez y se procedió a lectura, donde una unidad $(U)$ de actividad de proteasas se define como la densidad óptica a $280 \mathrm{~nm}$ dividido en el tiempo de reacción (15 minutos) (Quevedo, 1999).

Determinación de hialuronidasa. El método utilizado para su determinación fue la turbidimetría, siendo esta la medida del grado de atenuación de un haz radiante que incide sobre partículas suspendidas en un medio, practicando la medición en el haz directamente transmitido. La determinación puede hacerse mediante un fotómetro normal de filtro fotoeléctrico o un espectrofotómetro con iluminación a la longitud de onda apropiada. El método fue estandarizado para el presente estudio en el laboratorio de sueros del Instituto Nacional de Salud (Quevedo, 1999), la metodología se basa en la formación de complejos relativamente insolubles, entre mucopolisacáridos ácidos aislados y bromuro de cetiltrimetilamonio, la cantidad de turbiedad que se desarrolla al adicionar el bromuro de cetiltrimetilamonio dentro de una solución de mucopolisacáridos ácidos es proporcional a la cantidad de mucopolisacáridos ácidos en el sistema.

Una alícuota de la enzima fue disuelta en $0.6 \mathrm{ml}$ de buffer fosfato ácido cítrico al $0.1 \mathrm{M}, \mathrm{pH} 5.3$, se incubó a $37^{\circ} \mathrm{C}$ durante 15 minutos con 200 microgramos $(\mu \mathrm{g})$ de condroitin sulfato, disueltos en $0.4 \mathrm{ml}$ de buffer fosfato ácido cítrico, al mismo tiempo, se preparó un tubo estándar con $200 \mu \mathrm{g}$ de sustrato y un tubo blanco con solo el buffer, al final del periodo de incubación se adicionaron $2 \mathrm{ml}$ de bromuro de cetiltrimetilamonio, la reacción se detuvo (llevando el pH a 12.5) produciendo la 
turbiedad, luego se mezcló por inversión, y la densidad óptica fue determinada dentro de un tiempo de 10 minutos, contra el tubo blanco, tomando las lecturas en espectrofotómetro a $400 \mathrm{~nm}$, la densidad óptica dada por el estándar, fue trazada contra la cantidad de mucopolisacáridos ácidos presentes en el tubo $(200 \mu \mathrm{g})$, constituyendo una curva de calibración a la que se enviaron las densidades ópticas de los tubos que contenían la muestra. La unidad $(U)$ de actividad de la enzima se expresa como la cantidad de enzima que produce un $50 \%$ de reducción de la turbiedad, dado por la cantidad inicial $(200 \mu \mathrm{g})$ de sustrato.

Fosfatasa alcalina. La enzima es rutinariamente determinada con el uso de Pnitrofenilfosfatasa, como sustrato, para esto se mezcló $1.0 \mathrm{ml}$ de la muestra con $1.0 \mathrm{ml}$ de buffer glicina- $\mathrm{NaOH}$ al $0.1 \mathrm{M}, \mathrm{pH} 9.5,1.2 \mathrm{ml}$ de P-nitrofenilfosfatasa al $0.001 \mathrm{M}, 0.3 \mathrm{ml}$ de $\mathrm{MgCl}_{2} 0.1 \mathrm{M}, 0.1 \mathrm{ml}$ de la muestra y $0.5 \mathrm{ml}$ de agua deionizada, se incubó a $37^{\circ} \mathrm{C}$ por 15 minutos y se adicionó $3 \mathrm{ml}$ de $\mathrm{NaOH}$ al $0.03 \mathrm{~N}$, la absorbancia fue medida en espectrofotómetro a $400 \mathrm{~nm}$, contra un blanco que contenía todos los reactivos excepto la muestra. Una unidad $(U)$ de fosfatasa alcalina es definida como la cantidad de enzima que libera 1 micromol $(\mu \mathrm{mole})$ de P-nitrofenol por minuto (Lee y Snake, 1979).

Fosfatasa ácida. Se mezclaron $0.5 \mathrm{ml}$ de O-carboxifenilfosfatasa al $0.0036 \mathrm{M}$, con $2.0 \mathrm{ml}$ de buffer acetato de sodio $0.15 \mathrm{M}, \mathrm{pH}$ de 5.0 y $0.5 \mathrm{ml}$ de agua deionizada, luego se adicionaron $0.5 \mathrm{ml}$ de la muestra, mezclando por inversión, se preparó un blanco con todos los reactivos excepto la muestra. Una unidad $(U)$ de actividad de la fosfatasa ácida que es equivalente a $1 \mu$ mole del sustrato (Ocarboxifenilfosfatasa), que es hidrolizada por minuto (Lee y Snake, 1979).

Determinación de fosfolipasa $\mathrm{A}_{2}$ (PLA $)$. Se disolvieron 0.68 gramos de agarosa A en $66.5 \mathrm{ml}$ de buffer fosfato de sodio $50 \mathrm{mM}, \mathrm{pH} \mathrm{7.5,} \mathrm{esta} \mathrm{mezcla} \mathrm{se} \mathrm{calentó} \mathrm{en}$ un baño de agua hasta su completa dilución, luego se fue enfrió a 52 grados para adicionar $1.2 \mathrm{ml}$ de cloruro de sodio $10 \mathrm{mM}, 16.5 \mathrm{ml}$ de lecitina $3.5 \mathrm{mM}$ y $1.02 \mathrm{ml}$ de eritrocitos de cordero previamente lavados 4 veces con buffer de fosfato, usando centrifugación a 1000 revoluciones por 30 minutos, se sirvió esta solución 
en una placa de vidrio a $52^{\circ} \mathrm{C}$, se dejó en reposo durante 30 minutos y se realizaron pozos de $2.5 \mathrm{~mm}$ y se sembraron 10 microlitros de la muestra en cada uno, se llevó a incubar durante 20 horas a $37^{\circ} \mathrm{C}$. La reacción de hemólisis puede detectase por el efecto de aclaración de la suspensión, debido a la presencia de la fosfolipasa $A_{2}$, produciendo un halo hemolítico alrededor del pozo (Quevedo, 1999).

Determinación de $5^{\prime}$-nucleotidasa. $0.3 \mathrm{ml}$ de 5 -Adenosin Monofosfato al $0.01 \mathrm{M}$, se adicionaron a $0.1 \mathrm{ml}$ de $\mathrm{MgCl}_{2}$ al $0.1 \mathrm{M}, 0.5 \mathrm{ml}$ de buffer de glicina- $\mathrm{NaOH}$ al 0.2 $\mathrm{M}, \mathrm{pH} 8.5$ y $0.2 \mathrm{ml}$ de la muestra, la mezcla se incubó a $37^{\circ} \mathrm{C}$ por 15 minutos (Lee y Snake, 1979). La liberación del fosfato inorgánico es estimada por colorimetría que consiste en completar la muestra a un volumen de $100 \mathrm{ml}$, adicionando 0.05 $\mathrm{ml}$ (una gota) de indicador de fenolftaleína, $4 \mathrm{ml}$ de molibdato de amonio y $0.5 \mathrm{ml}$ de cloruro estañoso, se agitó y se leyó en espectrofotómetro a 690 nm (INS, 1991).

El perfil de accidentalidad con rayas consistió en una recopilación de datos obtenidos del registro de consulta de urgencias del Hospital Departamental de Villavicencio, correspondiente al año 2000. De las diferentes historias clínicas, se tomaron datos de síntomas presentados, frecuencia de casos por meses, miembros afectados, tratamientos instaurados en el centro hospitalario y técnicas inapropiadas aplicadas al momento del accidente.

\section{RESULTADOS}

\section{Proteasas}

La actividad de proteasas es medida utilizando como substrato caseína, la cual reacciona con las proteasas, produciendo la liberación de aminoácidos que no son precipitados por el ácido tricloroacético, quedando en el sobrenadante y produciendo cambios de absorbancia que son leídos en espectrofotómetro a 280 $\mathrm{nm}$, como control positivo al método se utilizó veneno de serpiente $B$. asper de la región de Armero, el cual permitió comprobar la eficiencia del método. La actividad 
de proteasas en los tres ensayos (E1, E2 y E3) realizados para el veneno de raya (Figura 1), mostraron una regresión lineal con semejanza en las pendientes (promedio 0.065 unidades $(\mathrm{U}) / \mathrm{mg}$ por minuto), con una medida de $0.01 \mathrm{U} / \mathrm{mg}$ por minuto y un intercepto de 0.0 , para los 2 ensayos realizados con el veneno de $B$. asper. En los ensayos E1 y E2, las rectas se superponen teniendo un término independiente semejante $(0.0181 \mathrm{U} / \mathrm{mg}$ por minuto), mientras que el E3 presenta un intercepto de $0.0518 \mathrm{U} / \mathrm{mg}$ por minuto.

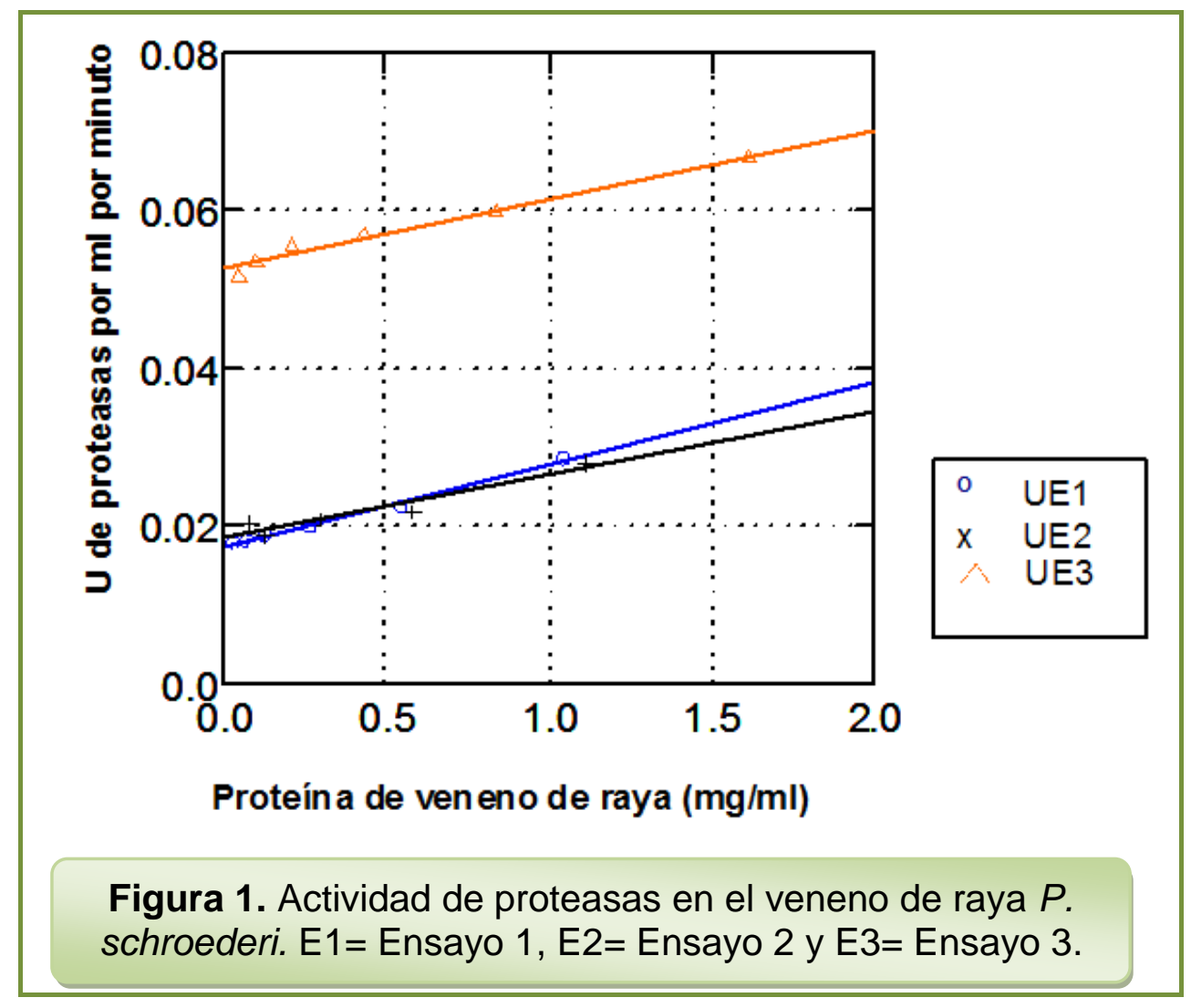

\section{Hialuronidasa}

Para verificar la eficiencia del método usado, se trabajó como control positivo una hialuronidasa purificada $(1 \mathrm{mg} / \mathrm{ml})$, la cual presentó una actividad de 212.58 unidades de hialuronidasa $(\mathrm{UH}) / \mathrm{ml}$ por minuto, mostrando que el método usado, sirve para la detección de esta enzima. No se utilizó el veneno de $B$. asper, como control positivo del método, debido a que no mostró resultados positivos a la actividad de la enzima hialuronidasa. Se realizaron varios ensayos de una misma 
muestra de veneno de raya ( $P$. schroederi), los cuales mostraron la presencia de la enzima hialuronidasa con una actividad de $0.178 \mathrm{UH} / \mathrm{ml}$ por minuto.

\section{Fosfatasa ácida}

Se utilizó el veneno de serpientes de la especie $B$. asper como control positivo del método, dando una actividad de 156.28 unidades $(\mathrm{U}) / \mathrm{mg}$ por minuto. Se trabajó con diferentes concentraciones de proteína del veneno de raya ( $P$. schroeder $)$, alcanzando una concentración de proteína de $32.82 \mathrm{mg} / \mathrm{ml}$ y no se encontró actividad de fosfatasa ácida.

\section{Fosfatasa alcalina}

Se utilizó como control positivo veneno de Bothrops asper, el cual mostró una actividad de $0.0028 \mathrm{U} / \mathrm{mgx}$ min y en el veneno de raya presentó para los ensayos realizados, una actividad de $0.519 \mathrm{U} / \mathrm{mg}$ por minuto, mostrando la presencia de fosfatasa alcalina en el veneno de raya $P$. schroederi.

\section{Fosfolipasa $A_{2}$}

Se utilizó como control positivo veneno de serpientes de B. asper (Figura 2), La mayor actividad (efecto dosis-respuesta) del veneno puede observarse en un rango de 6.3 a $13 \mathrm{~mm}$, para los ensayos realizados. La técnica fue aplicada al veneno de raya ( $P$. schroederi), hasta una concentración de proteína de 23.48 $\mathrm{mg} / \mathrm{ml}$, la cual no produjo halo hemolítico, no pudiendo demostrar la presencia de la enzima PLA2 en este veneno. Sin embargo, se observó un halo no hemolítico, evidenciado por una zona roja de mayor intensidad alrededor del pozo; se tomó la medida de dicho halo en los diferentes ensayos encontrándose en un rango entre 4.7 a $5.1 \mathrm{~mm}$, utilizando una concentración de proteína entre 8 a $23.48 \mathrm{mg} / \mathrm{ml}$. También se realizaron ensayos para la detección de la PLA $A_{2}$ directa, la cual no requiere la presencia de lecitina para ocasionar la lisis de las membranas del eritrocito, esto fue probado para el veneno de $P$. schroederi y $B$. asper, no mostrando resultados positivos para ninguno de los dos casos. 


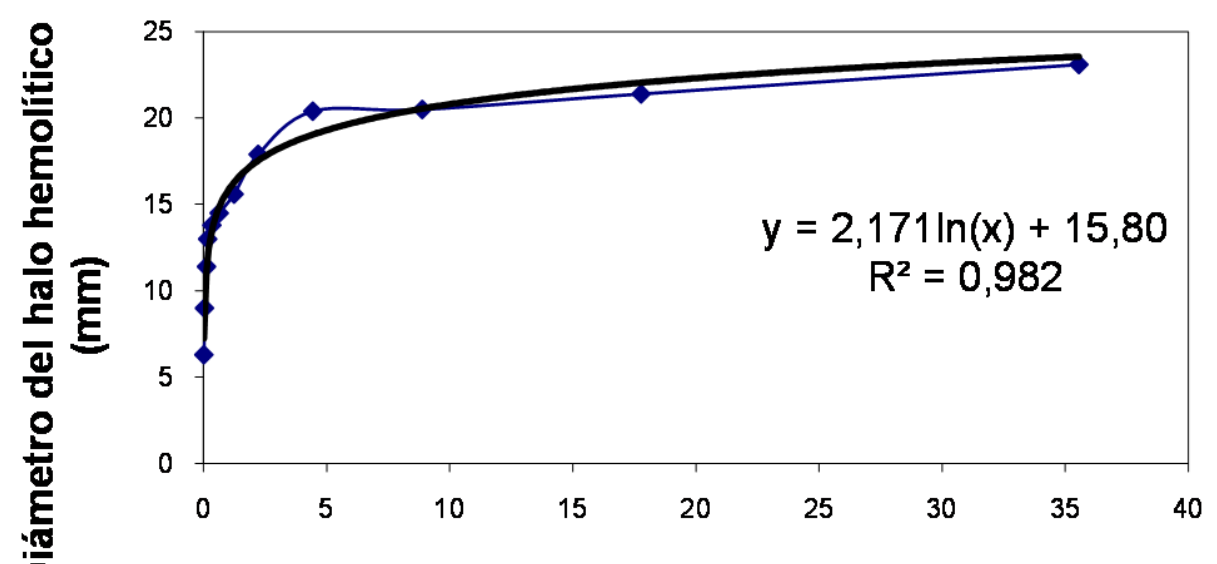

Proteína del veneno de $B$. asper $(\mathrm{mg} / \mathrm{ml})$

Figura 2. Efecto de la concentración del veneno de $B$. asper en la actividad hemolítica por efecto de la PLA ${ }_{2}$.

\section{5'-nucleotidasa}

La 5'-nucleotidasa es una enzima que se encuentra en todos los venenos de serpientes hasta ahora examinados, razón por la cual, se aplicó la técnica a diferentes venenos de serpientes de Colombia, mostrando actividad para todos los venenos examinados (Figura 3 ), y para el veneno de raya ( $P$. schroederi), siendo esta última, cerca de tres veces más activa que los venenos de serpientes, en los ensayos realizados.

\section{Perfil de accidentalidad por rayas en un año}

Se presentan en promedio 20 accidentes en el año, con la distribución por meses (Figura 4), de los cuales presentados 17 fueron en adultos (85\%) y 3 fueron a niños (15\%), así mismo las lesiones en miembro inferior fueron mayores 18 casos $(90 \%)$ y $2(10 \%)$ en miembro superior. La casuística posiblemente se relaciona con la época del año, debido a que los meses de Enero, Febrero, Septiembre y Diciembre, fueron los en los que se presentaron mayor números de casos, asociando con los bajos niveles de agua en los ríos y a que las rayas son peces que se encuentran habitualmente en las orillas de los ríos, aunado a este hecho 
los bañistas acceden a los ríos en verano, aumentando así la probabilidad de accidentes. Se observan los diferentes síntomas presentados en los 20 casos de accidentes por rayas en el Hospital Departamental de Villavicencio (Tabla 1).

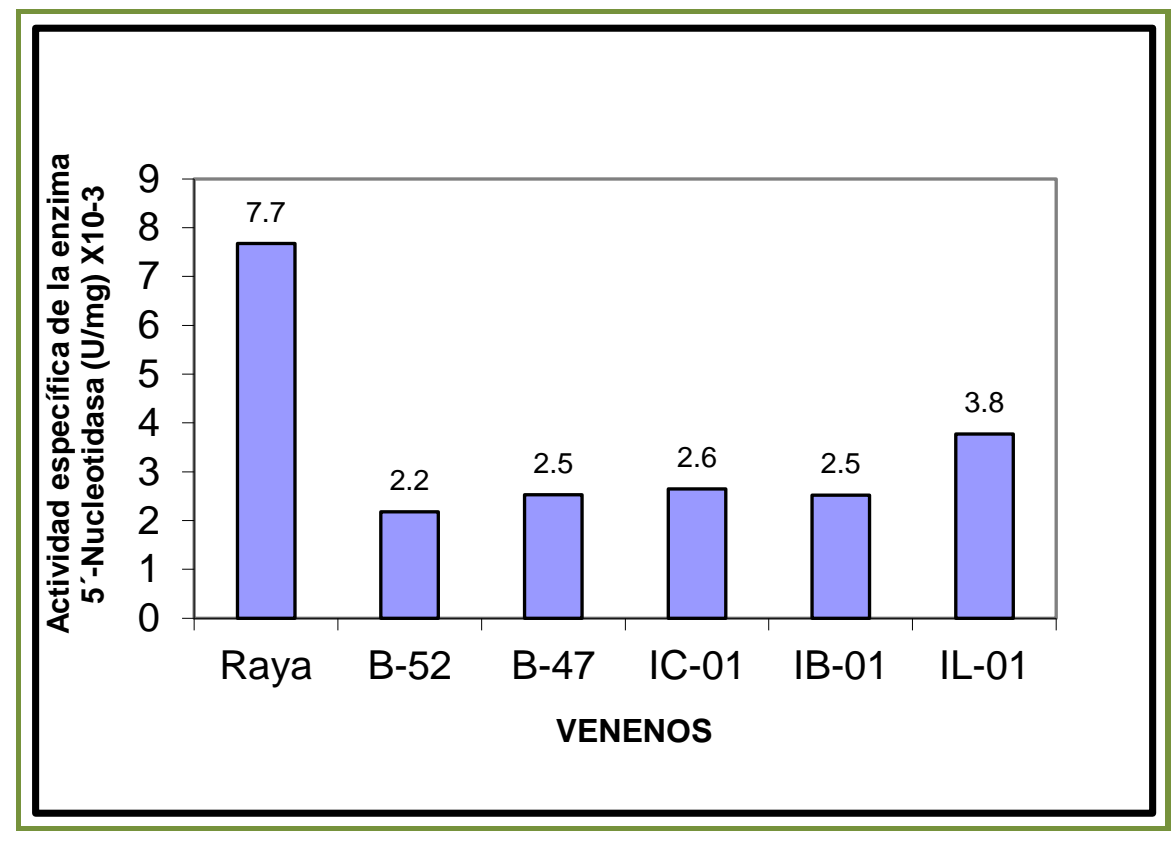

Figura 3. Actividad específica de la enzima $5^{\prime}$-nucleotidasa en los venenos de Raya ( $P$. schroederi) Bothrops asper, Armero (B-52), Bothrops asper, Chiriguaná (B-47), pool de venenos del género (PVG) Crotalos de Colombia (IC-01), PVG Bothrops de Colombia (IB-01), PVG Lachesis de Colombia (IL-01).

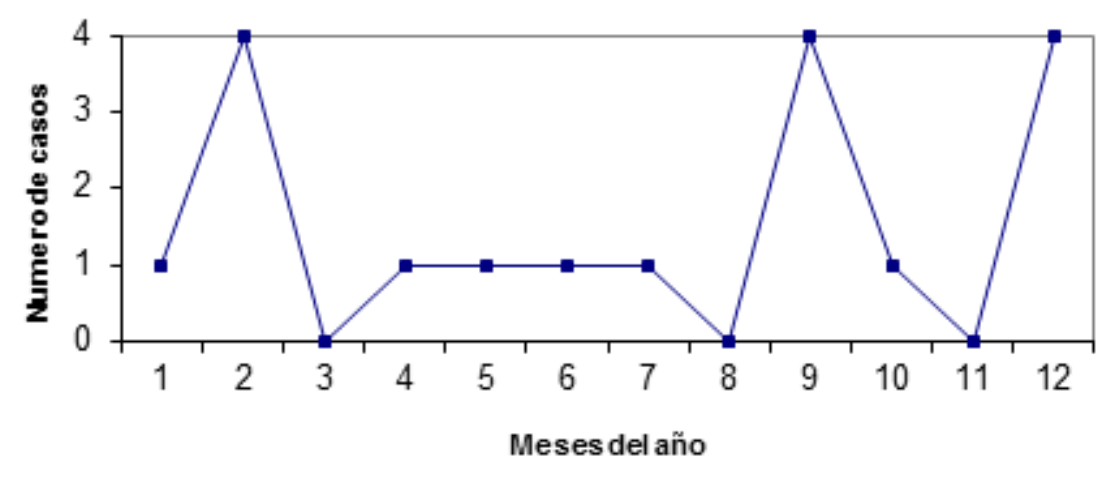

Figura 4. Número de casos de accidentes ocasionados por rayas en el Hospital Departamental de Villavicencio, en un año. 
Tabla 1. Síntomas presentados en los accidentes con rayas, Hospital Departamental de Villavicencio, en un año.

\begin{tabular}{ccc}
\hline Síntomas y consecuencias & Casos & \% Incidencia \\
\hline Dolor & 20 & 100 \\
Celulitis & 2 & 10 \\
Edema & 8 & 40 \\
Necrosis & 4 & 20 \\
Ulceras & 1 & 5 \\
Amputación o remoción parcial & 4 & 20 \\
\hline
\end{tabular}

Los tratamientos no médicos aplicados en el momento del accidente, fueron: plantas medicinales, hiel de lapa, orines, sal y cebolla con limón, en el sitio de la picadura, además consumo de alcohol por el paciente. Ninguna de las historias clínicas, evaluó parámetros hematológicos al momento de la lesión o posterior a ella. Los tratamientos instaurados en el centro hospitalario evidenciaron la carencia de aplicación de toxoide tetánico, el cual está indicado en cualquier tipo de accidente, además el uso de técnicas poco ortodoxas, como aplicación de sustancias inapropiadas, en un momento dado pueden agravar el cuadro clínico del paciente.

\section{DISCUSIÓN}

Para la realización de los ensayos se trabajaron 12 arpones de diferentes tamaños y diferentes concentraciones de proteína. Al realizar el análisis de los datos para correlacionar el contenido de proteína $(\mathrm{mg} / \mathrm{ml})$, con la longitud $(\mathrm{cm})$, de los arpones se encontró que existe una relación lineal entre estos valores. De igual manera, se correlacionó la cantidad de raspado $(\mathrm{mg})$ y el contenido de proteína $(\mathrm{mg} / \mathrm{ml})$, demostrando que existe una relación lineal entre la cantidad del raspado y la proteína. Los resultados demuestran que entre más largo sea un arpón, mayor contenido de proteína va a tener, observando una relación de $0.95 \mathrm{mg} / \mathrm{ml}$ de proteína por cada centímetro de arpón. De igual forma entre mayor cantidad de raspado se obtenga, mayor será el contenido de proteína, con una medida de 0.86 mg de proteína por $1 \mathrm{mg}$ de raspado. 
Las proteasas debido a su actividad proteolítica, causan el fenómeno de muerte celular conocido como necrosis. El veneno de Bothrops asper fue utilizado como control positivo, mostrando una actividad aproximadamente 6 veces mayor que el veneno de raya. Además, en el veneno de raya se observó un intercepto que varía de un arpón a otro, lo cual podría deberse a una diferencia entre arpones por la presencia de alguna sustancia no precipitable que presenta absorción en espectrofotómetro a $280 \mathrm{~nm}$, como es el caso de aminoácidos, este efecto no se observó en el veneno de $B$. asper, para los ensayos realizados.

La hialuronidasa es una enzima que causa la hidrólisis del ácido hialurónico, el cual es el componente extracelular del tejido conectivo que controla el estado de hidratación y el tráfico de macromoléculas en la matriz tisular e interviene especialmente en la regeneración post inflamatoria, con actividad específica en la migración de los fibroblastos y la fibrogénesis (Habasseda, 2001). Los resultados obtenidos en el veneno de raya (Potamotrygom schroederi) mostraron la presencia de hialuronidasa, con una actividad de 0.178 unidades de hialuronidasa (UH)/mg por minuto.

Las fosfatasas pertenecen al grupo o de las fosfomonoesterasas, hidrolizan compuestos biológicamente importantes, relacionados con la producción de energía 8P-nitrofenolfosfato, el fenilfosfato, 2-AMP, 3-AMP, glucosa 1 y 6 fosfato y ácido glicerofosfórico (Tu, 1977). Este desbalance entre el consumo y la reposición de energía ocasiona edema e isquemia tisular, con eventual necrosis. De igual forma, a nivel sistémico los productos de la hidrólisis del ATP y AMP, son componentes tóxicos que causan disminución de la presión sanguínea. La fosfatasa ácida en el veneno de $B$. asper utilizado como control positivo, mostró la eficiencia del método, sin embargo, el veneno de raya no mostró presencia de esta enzima hasta una concentración de proteína de $32.82 \mathrm{mg} / \mathrm{ml}$. La fosfatasa alcalina en el veneno de raya $(P$. schroederi) mostró una actividad de $0.519 \mathrm{U} / \mathrm{mg}$ por minuto, es decir una actividad 185 veces superior en comparación con el veneno de $B$. asper $(0.0028 \mathrm{U} / \mathrm{mg}$ por minuto), en los ensayos realizados. 
La enzima fosfolipasa $A_{2}$ pertenece a una familia de proteínas relacionadas antigénicamente y con estructuras químicas semejantes y agrupadas por la producción de hemólisis. Algunas PLA 2 aisladas del veneno de serpientes e inyectadas en tejido muscular de mamíferos, conducen a una serie de drásticos eventos degenerativos que probablemente se inicien en la membrana plasmática y culminan con necrosis selectiva de músculo esquelético. Se supone que el efecto miotóxico es provocado por interacción electrostática con la membrana y posterior penetración de la bicapa (Gutiérrez y Lomonte, 1995), y los efectos causados por $\mathrm{PLA}_{2}$ inducen a desestabilización de la membrana, con pérdida selectiva de la permeabilidad del ion $\mathrm{Ca}^{++}$, mediador importante en el proceso de necrosis muscular. Sin embargo, la PLA 2 induce otras alteraciones patológicas importantes, tales como: neurotoxicidad, acción cardiotóxica, hemólisis, efecto anticoagulante y actividad inductora de edema. En el grupo control el veneno de Bothrops asper, mostró resultados positivos, mientras que en el de la raya ( $P$. schroederi), no existió la formación de halo hemolítico por acción directa o indirecta de la PLA2. Sin embargo, con veneno de $P$. schroederi en la prueba de hemólisis indirecta, se formo un halo de coloración intensa alrededor del pozo, pero sin evidencia de hemólisis, lo que sugiere que el cambio en la coloración puede deberse a un efecto sobre la membrana del eritrocito, que no puede ser atribuido a la fosfolipasa $\mathrm{A}_{2}$.

La 5'-Nucleotidasa es una enzima que causa la hidrólisis específica de los monoesteres fosfatos con las uniones en la posición 5 del DNA y el RNA y también hidroliza dos o tres fosfatos de adenosina, guanosina, entre otros. Los venenos de algunas serpientes de Colombia fueron analizados junto con el veneno de raya, encontrando que el veneno de raya ( $P$. schroederi), era aproximadamente tres veces $\left(7.7 \times 10^{-3}\right)$ más activo que los venenos de serpientes. 


\section{Modelo fisiopatológico del veneno de raya (Potamotrygom schroederi)}

Debido a la carencia de trabajos conducentes a la determinación de la composición enzimática del veneno de la raya de agua dulce y a la subestimación de los accidentes presentados se buscó dar un modelo explicativo de la fisiopatología del veneno de la raya $P$. schroederi, basado en la acción individual de las enzimas sobre componentes del organismo vivo.

Entre los síntomas presentes en accidentes con rayas, esta la necrosis tisular, y edema celular (Meier y Acoot, 1995; The Merck, 1999), lo cual se confirmó con un perfil de accidentalidad, realizado en el Hospital Departamental de Villavicencio, en donde 4 de 20 casos (20\%), presentaron necrosis tisular y 8 de los 20 casos (40\%) edema. Esta sintomatología presentada probablemente podría explicarse de acuerdo con los resultados encontrados en este estudio, a la acción combinada de las enzimas: hialuronidasa, proteasas, fosfatasa alcalina y $5^{\prime}$-nucleotidasa, descartando que algunos síntomas sean ocasionados por la presencia de fosfolipasa $A_{2}$ y la fosfatasa ácida.

La formación de necrosis tisular puede ser explicada como el desencadenamiento de una cascada de fenómenos que probablemente inician con la acción de la hialuronidasa, causando destrucción del ácido hialurónico, provocando una pérdida de agua y permitiendo la difusión de enzimas toxicas dentro de las víctimas como: fosfatasa alcalina, 5'-Nucleotidasa y proteasas, siendo estas últimas responsables de causar la hidrólisis de proteínas de los tejidos, produciendo la muerte celular.

La destrucción de los tejidos podría continuar probablemente con la acción de la fosfatasa alcalina y $5^{\prime}$-nucleotidasa, que actúan produciendo la hidrólisis de los esteres fosfatos, de nucleótidos y nucleosidos. La hidrólisis del ATP y el aumento del AMP, agotamiento de las reservas energéticas, ocasionando un desbalance entra la reposición y el consumo de ATP, lo cual se encuentra asociado a la disminución del flujo tisular de electrones mitocondriales, con la consecuente disminución de la presión de oxigeno tisular, debido a esto se produce isquemia y 
acumulación de radicales que causan daño celular y degradación de los ácidos nucleicos. Al mismo tiempo se disminuye el pH por acumulación de ácido láctico y fosfatos inorgánicos (producto de la hidrólisis de esteres fosfatos), produciendo lesión en las membranas lisosomales, permitiendo la salida de enzimas al citosol, las cuales producen la autodigestión y muerte celular (necrosis).

La producción de edema posiblemente se produce por la falla de la bomba de sodio (de alto consumo energético), el sodio empieza a entrar a la célula y consigo el agua, dilatando el retículo endoplasmático, mitocondrias y aparato de Golgi. (Raffan y Kling, 2001). De esta manera, se puede aproximar la acción de las enzimas encontradas en el organismo vivo (proteasas, hialuronidasa, fosfatasa alcalina y 5 '-nucleotidasa), las cuales pueden en un momento dado estar asociadas con el daño sobre los tejidos, ocasionando una isquemia tisular, edema y eventual necrosis. Una vez instaurado el efecto de necrosis sobre los tejidos, la resolución del daño y el cierre del trauma mecánico, se ve afectado por la destrucción del ácido hialurónico, a causa de la hialuronidasa, lo cual impide la cicatrización. A nivel sistémico los productos de la hidrólisis de ATP y AMP, por la 5 'nucleotidasa y fosfatasa alcalina, son componentes tóxicos que causan disminución de la presión sanguínea (Bücherl y Buckley, 1968). El veneno de raya es considerado como cardiotóxico (raya Urolophus halleri), esto se podría explicar por la presencia de la $5^{\prime}$-nucleotidasa, y por la acción de la fosfatasa alcalina en el veneno de raya $(P$. schroederi). La acción de la 5 '-nucleotidasa en el organismo vivo, bajo condiciones de isquemia de las células que han perdido la capacidad de la síntesis de ATP, llegando a producir solo AMP, y adenosina, que es una sustancia poderosamente vasodilatadora, la cual disminuye la perfusión coronaria e incrementa el desbalance entre la oferta y demanda de oxigeno (Castro, 2001).

\section{CONCLUSIONES}

Los resultados obtenidos demuestran claramente la importancia de la accidentalidad ocasionada por las rayas de agua dulce, debido a que su veneno posee una mezcla enzimática de proteasas, fosfatasa alcalina, hialuronidasa y 5 '- 
nucleotidasa, que fisiopatológicamente podrían causa en el individuo alteraciones locales y sistémicas, lo cual hace necesario definir diferentes grados de envenenamiento y crear políticas de tratamientos en los diferentes hospitales, dejando de lado la creencia de que las rayas no son peces venenosos, ya que esta consideración lleva a las personas a subestimar la importancia del accidente, generando complicaciones mayores de los mismos.

\section{RECOMENDACIONES}

Realizar estudios que permitan obtener los orígenes e inserciones de los diferentes músculos que conforma la cola, con el fin de ver en mayor detalle su función. Establecer la relación que existe entre el tamaño del animal y el tamaño del arpón. Realizar trabajos más profundos (inmunohistoquímica o hibridación in situ), de las células serosas, con el fin de confirmar que realmente son las productoras de veneno.

En ninguno de los casos presentados en el Hospital Departamental de Villavicencio, se evaluaron parámetros hematológicos, lo cuales deben ser evaluados en cualquier caso de envenenamiento por rayas para determinar la influencia del veneno a nivel sistémico.

\section{REFERENCIAS BIBLIOGRÁFICAS}

1. Arizona State University (ASU). Standard Operating Procedures for Fishes. 1999. Recuperado 10 de Junio de 2010. Disponible En: http://researchnet.asu.edu/animal care/animal information/fish info.html

2. Auerbach S., P. Marine envenomations. New Eng. J. of medice., 325: 486-493, 1991.

3. Bücherl W., Buckley E. E. Venomous animals and their venoms: Venomous vertebrates. London: Academic press, 1: 167-216. 1968.

4. Cala P. Nuevos registros de peces para la Orinoquia colombiana. Unellez de Ciencia y Tecnología, 4: 89-112, 1986.

5. Castro A. R. Fisiología de la circulación coronaria. 2001. Recuperado 10 de Diciembre de 2010.2 Disponible En: www.infomedonline.com.ve/cardiopatia/fisiol.htm

6. Collective Review. Stingray injuries. 1999 Recuperado 5 de Febrero de 2010. Disponible En: www.wadingboot.com/collective review.htm

7. Dahl, G. Los peces del norte de Colombia. Bogotá: INDERENA, 25-38. 1971. 
8. Grenard S. Stingray injures envenomation, and medical magnament. Recuperado 20 de Junio de 2009. Disponible En: www.private.add.com.e/potamotrygom/fremdes/stingray\%article.html

9. Gutiérrez J. M., Lomonte B. Phospholipase A2 Myotoxins from Bothrops snake venoms. Toxicon. 33 (11): 1405-1424. 1995.

10. Habasseda X. Ácido hialurónico. 2001. En: Drugs of today. Recuperado 10 de Diciembre de 2010.2 Disponible En: www.sdpt.net/Farmacologia/acido\%20hialuronico.pdf

11. Instituto Nacional de Salud Colombia (INS). Análisis de agua para el consumo humano. Subdirección de epidemiología y laboratorio nacional de referencia. Laboratorio red salud ambiental. Santafé de Bogotá: Ministerio de Salud, 1991.

12. Lee, Y. Snake venoms: Hadbook of experimental pharmacology. Board, Springer-Verlag. Berlin Heidelberg. New York, 52: 93-100, 1979.

13. Meier J., Acott C. Clinical toxicology of venemous stingray injures. En: White J. and Meier J. Clinical toxicological of animal venoms and poison. London: CRC press, p 135-140, 1995.

14. Mojica C, J. Lista preliminar de las especies de peces dulceacuícolas de Colombia. Revista de la Academia Colombiana de Ciencias Exactas, Físicas y Naturales, 23: 547-566, 1999.

15. Otero, R., Gutiérrez, J., Mesa, M.B., Duque, E., Rodríguez, O., Aranga, J.L., Gómez, F., Toro, A., Cano, F., Rodríguez, L.M., Caro, E., Martínez, J., Cornejo, W., Gómez, L.M., Uribe, F.L., Cárdenas, S., Nuñez, V., Diaz, A., Complications of Bothrops, 66 Porthidium, and Bothriechis snakebites in Colombia. A clinical and epidemiological study of 39 cases attended in a university hospital. Toxicon 40: 1107-1114. 2002.

16. Petrovicky I. La gran enciclopedia de los peces de acuario. Susaeta. Madrid, p 32-33, 1990.

17. Pineda D., Rengifo J.M. Accidentes por animales venenosos. Santafé de Bogotá, Instituto Nacional de Salud, p 31-63, 2002.

18. Quevedo H., B. Purificación y determinación de algunas características de la enzima fosfolipasa en el veneno de Bothrops atrox (taya X), proveniente de Chiriguaná, Cesar, 139 p. Santafé de Bogotá, 1999. Trabajo de grado (químico). Universidad Nacional de Colombia. Facultad de Ingeniería. Departamento de Ingeniería.

19. Raffan S. F., Kling G. J. Síndrome de reperfusión. 2001 Recuperado 8 de Noviembre de 2010.2 Disponible En: www.scare.org.co/publicaciones/recursos/RCA.../síndrome\%20de20reperfusion. html

20.Santoro M.L., Sano-Martins I.S. Platelet dysfunction during Bothrops jararaca snake envenomation in rabbits. Journal of Thrombosis and Haemostasis 92 : 369-83, 2004.

21. Tu T. A. Venoms: Chemistry and molecular biology. New york: A wiley interscience publication, p 23-63. 1977.

22. The Merck. Venomous bites and Stings. Manual. Home edition. Sec. 24, Ch. 287. Recuperado 5 de diciembre de 1999. Disponible En: www.merck.com/pubs/mmanual home/sec24/287.htm 